\title{
Experimental study on the formation of non-metallic inclusions acting as nuclei for acicular ferrite in HSLA steels through specific deoxidation practice and defined cooling conditions
}

\author{
Susanne K. Michelic ${ }^{1, a}$, Denise Loder ${ }^{1, b}$ Gregor Arth $^{1, c}$ \\ and Christian Bernhard ${ }^{1, d}$ \\ ${ }^{1}$ Chair of Ferrous Metallurgy, Montanuniversitaet Leoben, Franz-Josef Straße 18, 8700 Leoben, \\ Austria \\ asusanne.michelic@unileoben.ac.at, ${ }^{\text {b }}$ denise.loder@unileoben.ac.at, \\ cgregor.arth@unileoben.ac.at, ${ }^{d}$ christian.bernhard@unileoben.ac.at
}

Keywords: non-metallic inclusions, acicular ferrite, HSLA steel, heterogeneous nucleation

\begin{abstract}
Specific types of non-metallic inclusions are known to act as heterogeneous nuclei for the formation of acicular ferrite, which provides excellent toughness. By increasing the amount of acicular ferrite in the microstructure, the properties of HSLA steels can be optimized significantly. Although the formation of acicular ferrite caused by heat treatments (thermomechanical treatments or welding) is quite well described in literature, there is less information to find about the formation of acicular ferrite immediately out of the liquid melt. Within the present study experiments on laboratory scale are carried out simulating the influence of cooling conditions and Ti-content on size, chemical composition and morphology of non-metallic inclusions and consequently on the amount of acicular ferrite. All experiments were carried out with a dipping test simulator enabling very well controllable cooling conditions. Optical microscopy in combination with special etching methods as well as SEM/EDS-analysis was used for microstructure and inclusion characterization.
\end{abstract}

\section{Introduction}

In the 1990s several studies concerning "Oxide Metallurgy" emerged [1-2] describing a scientific field that has been developed with the aim of achieving microstructure control through the appropriate tailoring of inclusions. In order to produce steels with a defined microstructure in combination with a possibly low content of harmful inclusions, the production process and the metallurgical treatments have a great impact. Originally, detailed studies on weldments in the fusion zone have accounted for the knowledge gained about the role of inclusions in controlling the grain size of steels [3-4]. Alternatively, there has been a considerable effort in recent years to find another method for grain refinement based on the high density of fine particles to nucleate ferrite inside the austenite grain with the help of thermomechanical treatments. Based on these first approaches [5] up to now some essential fundamental work has been done describing this relationship between the presence of inclusions and the development of acicular ferrite (AF) structures, mainly focusing on so-called HSLA (High Strength Low Alloyed) steels [6-7].

Various authors reported that an increased content of AF in the microstructure leads to an improvement of the mechanical properties [6-7] due to the significant differences in the propagation path for a cleavage crack in different microstructures. Principally, the nucleation of acicular ferrite can be affected by steel composition, cooling rate, austenite grain size as well as non-metallic inclusions [6-7]. As far as inclusions are concerned, next to inclusion size and number also the chemical composition of inclusions essentially affects the acicular ferrite formation [7-10]. Sarma et al. [7] give a comprehensive review on the influence of inclusion composition on the nucleation of acicular ferrite: In general, single phase inclusions like simple oxides or sulfides are not expected to act as heterogeneous nuclei for acicular ferrite. In contrast, complex inclusions are seen to act as more active nuclei for AF. Secondly, one of the most commonly stated effects in literature is nucleation arising from solute depletion of elements in the matrix near inclusions [11-13]: In this context particularly the effect of the Mn-depleted zone is discussed in literature. 
The present study mainly focuses on the adjustment of the cleanness level in a HSLA steels directly in the liquid melt through specific deoxidation and defined cooling conditions without any separate addition of particles. For this purpose experiments with a so-called dipping test simulator were performed on laboratory scale. Especially the effect of Ti-content as well as cooling conditions on the final inclusion landscape and therewith connected microstructure has been studied.

\section{Experimental Procedure}

The used experiment is based on the principle of a dipping test under inert gas atmosphere inside a vacuum induction furnace (see Fig.1). This apparatus is equipped with a pyrometer in order to measure the temperature of the solidified sample during the subsequent cooling phase. Different cooling strategies or heat treatments can be selected by the use of conventional heat treatment furnaces or by quenching the samples in water. Thus, it is possible to reproduce solidification and subsequent cooling of the cast material in casting-rolling processes and to characterize the microstructure and the mechanical properties of the solidified samples.

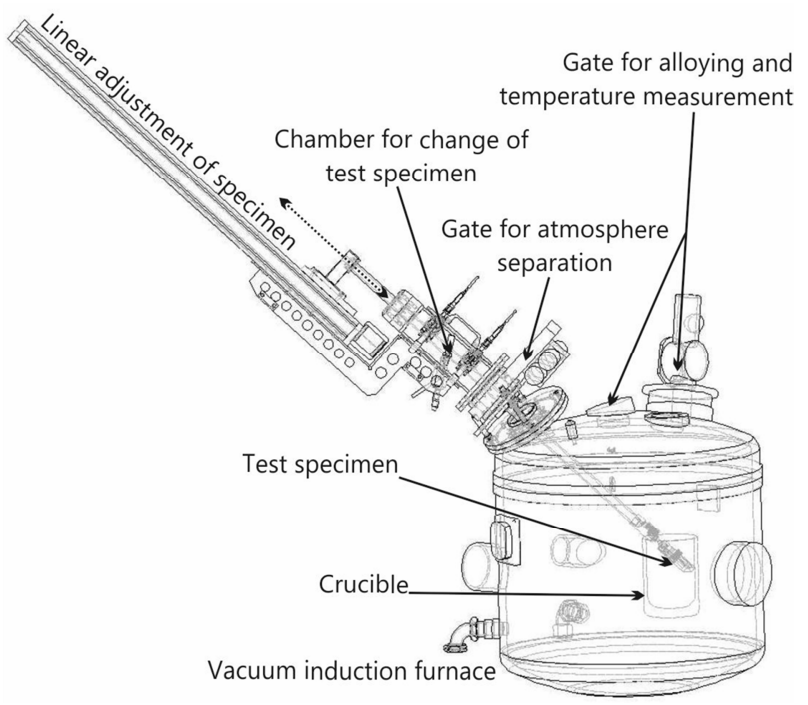

Fig.1. Main parts of the dipping test assembly [14-15].

A steel melt was built up in the vacuum induction furnace and deoxidized with FeSi. No separate aluminum was added. Titanium was alloyed after deoxidation to get a defined initial oxygen level and inclusion landscape. The dipping tests were carried at a temperature of $1570{ }^{\circ} \mathrm{C}$. Four different steel compositions with increasing Ti-content were examined; their chemical compositions are given in Table 1.

Table 1. Chemical Composition of the investigated steels [wt $\%$ ].

\begin{tabular}{ccccccc}
\hline $\mathrm{C}$ & $\mathrm{Si}$ & $\mathrm{Mn}$ & $\mathrm{P}$ & $\mathrm{S}$ & $\mathrm{Al}$ & $\mathrm{Ti}$ \\
\hline 0.23 & 0.07 & 1.5 & 0.002 & 0.002 & 0.002 & $0.05 / 0.1 / 0.2 / 0.36 / 0.45$ \\
\hline
\end{tabular}

The test specimen consists of a metallic substrate surrounded by a ceramic fiber material and is attached onto the linear adjustment of the dipping test simulator. After preheating the specimen to $200-230{ }^{\circ} \mathrm{C}$ it gets accelerated into the liquid metal melt and remains there for a defined time. During this period the liquid steel solidifies onto the metallic substrate. By increasing the time of the specimen inside the melt a sample thickness of up to $7 \mathrm{~mm}$ can be reached. For this experiment three different holding times in the melt (dip times) from $0.25-10 \mathrm{~s}$ were used. After reacceleration of the sample back into the chamber of the simulator, the optical measurement of the surface temperature starts. The sample can remain in the chamber for cooling or can be taken out of the chamber for water quenching or different heat treatments (see Fig.2). 


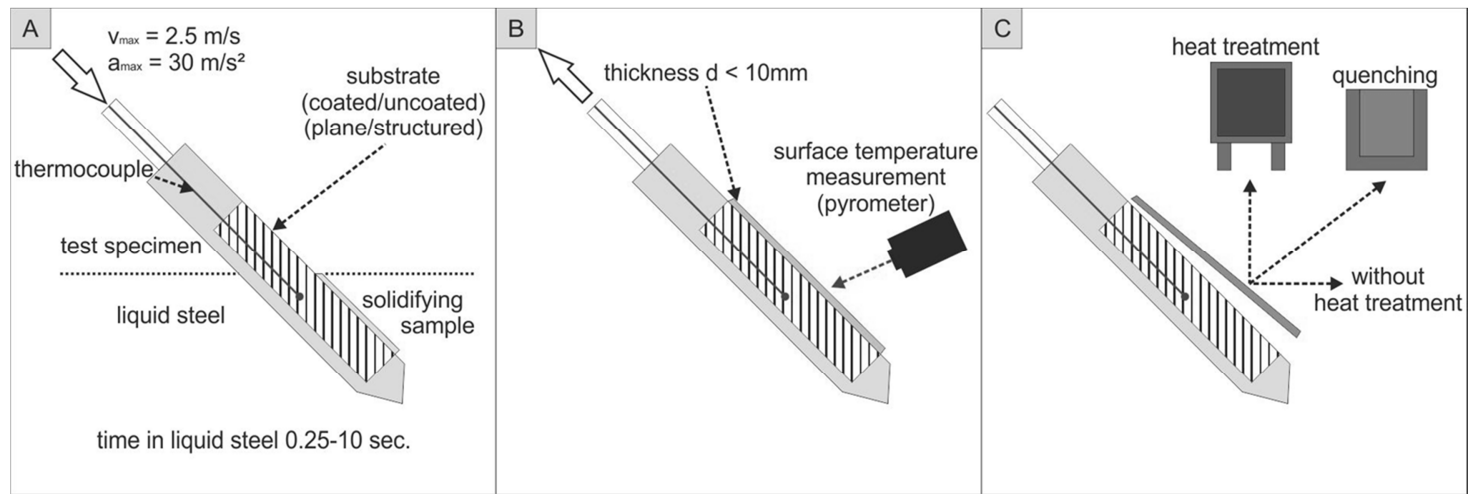

Fig.2. Dipping test with subsequent pyrometer measurement and optional heat treatment [14-15].

Based on the variation of dip times and the use of different cooling systems, four cooling strategies have been applied, whose cooling curves are shown in Fig.3. Simultaneously with every dip sample a tube sample was taken, which was used for chemical analysis by spark spectrometry as well as for $\mathrm{O}-$ and $\mathrm{N}$-measurements by inert gas fusion infrared and thermal conductivity detection.

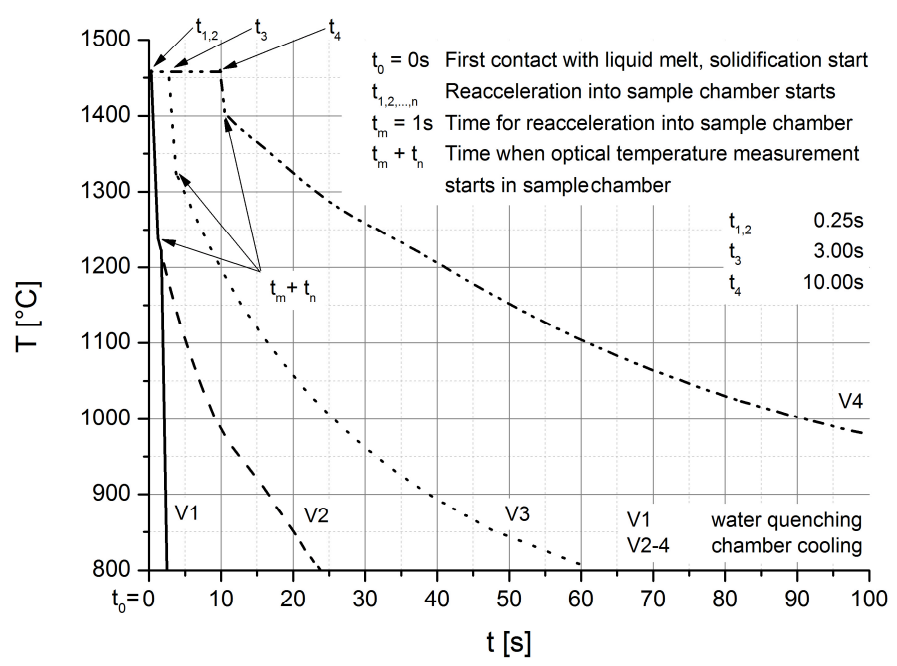

Fig.3. Cooling curves of dipping tests.

Metallographic examinations of these dipping test samples have subsequently been used for microstructure investigations and inclusion characterization. The samples were etched with Nital $3 \%$ and examined with optical microscopy and SEM/EDS.

\section{Microstructure Characterization and Inclusion Analyses}

The etched samples were characterized concerning their microstructure in dependence of steel composition and cooling rate. Thereby special attention was paid to the determination of the acicular ferrite amount in microstructure. The maximum acicular ferrite amount was achieved at the lowest tested Ti-level of $0.05 \%$, with increasing Ti-content the amount of acicular ferrite decreases significantly. Above $0.2 \% \mathrm{Ti}$ in the steel, no acicular ferrite was formed; the samples show a bainitic/martensitic microstructure. Fig.4 illustrates the change of microstructure with increasing Ti-content for a cooling rate of $3{ }^{\circ} \mathrm{C} / \mathrm{s}$ from mainly acicular ferrite with fractions of Widmannstätten ferrite, grain boundary ferrite and bainite/martensite, changing to a microstructure of mainly bainite/martensite with locally acicular ferrite nucleation (marked by arrow) ending up in a pure bainitic/martensitic structure.

A very strong influence on the amount of acicular ferrite was achieved by variation of the cooling rate. Starting with a very high cooling rate of about $400{ }^{\circ} \mathrm{C} / \mathrm{s}$ for water quenched samples (cooling rate $\mathrm{V} 1$ ) resulting in a pure martensitic structure, a decrease of cooling rate leads to an increase of 
acicular ferrite amount in microstructure. The maximum acicular ferrite amount can be achieved with cooling rate $\mathrm{V} 3$, where the sample was cooled with approximately $7^{\circ} \mathrm{C} / \mathrm{s}$ between 800 and $600{ }^{\circ} \mathrm{C}$. A further decrease of cooling rate to $3{ }^{\circ} \mathrm{C} / \mathrm{s}$ (V4) does not result in a further increase of acicular ferrite; in contrast, acicular ferrite amount is significantly lower than for cooling rate V3. Fig.5 illustrates the influence of cooling rate on microstructure exemplary for a Ti-level of $0.05 \%$.
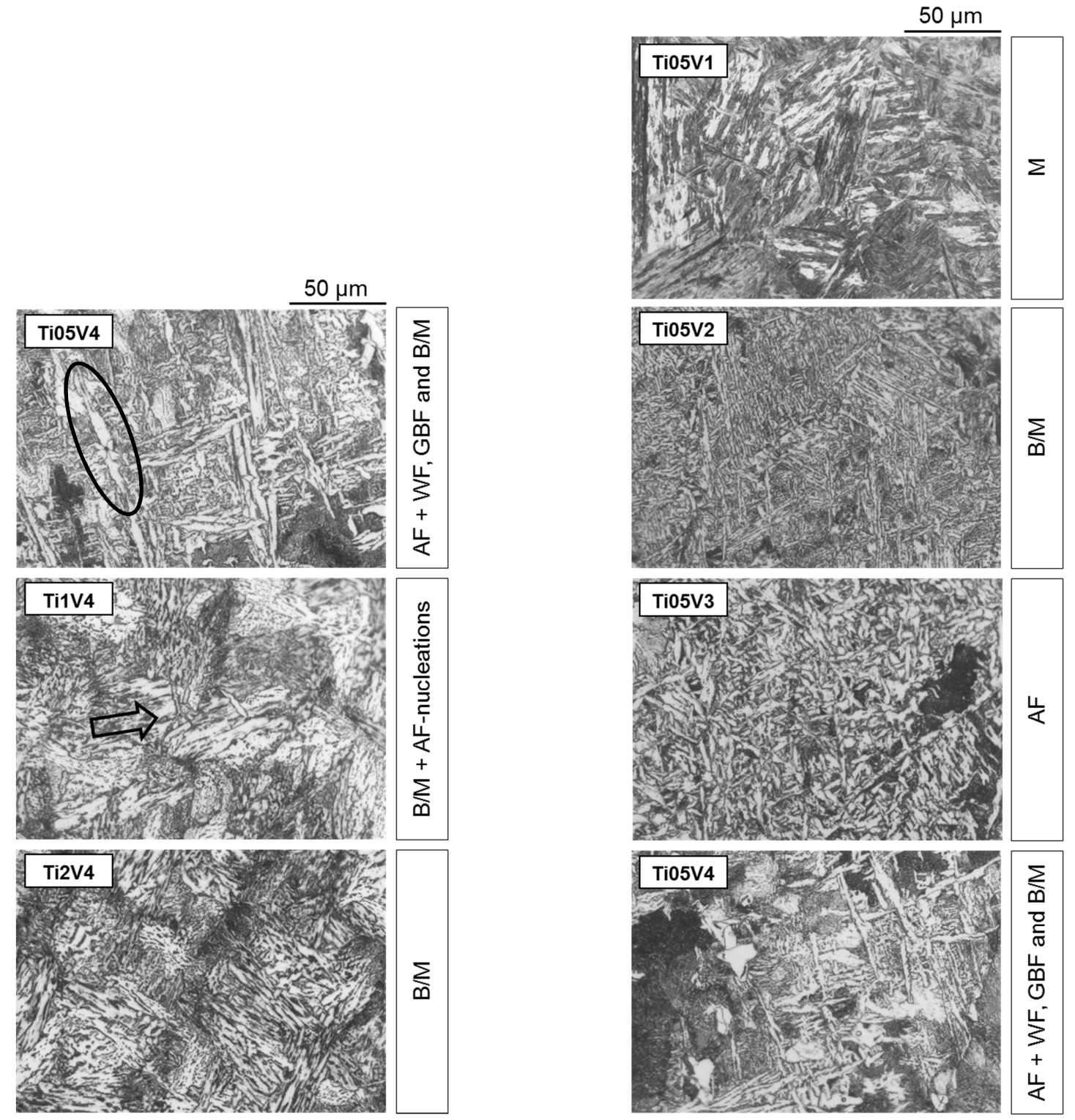

Fig.4. Influence of Ti-content on microstructure

(AF: acicular ferrite, WF: Widmannstätten ferrite, GBF: grain boundary ferrite, B/M: bainite/martensite).

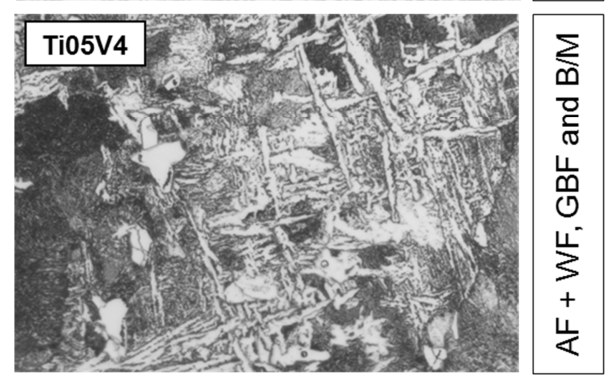

Fig.5. Influence of cooling rate on microstructure (M: Martensite, B: bainite, AF: acicular ferrite, WF: Widmannstätten ferrite, GBF: grain boundary ferrite).

On the left side of image Ti05V4 in Fig.4 the nucleation of acicular ferrite on a non-metallic inclusion can be seen clearly (marked with a circle). Acicular ferrite grains grow starting from the inclusion in all directions. SEM/EDS-analyses were done to analyse the inclusion landscape in the dipping samples and to get information about the type of active inclusions for the nucleation of AF. These analyses show that active inclusions are complex inclusions combining oxides and sulphides, which are mainly consisting of Titanium, Manganese, Aluminium, Oxygen and Sulphur (see Fig.6). 

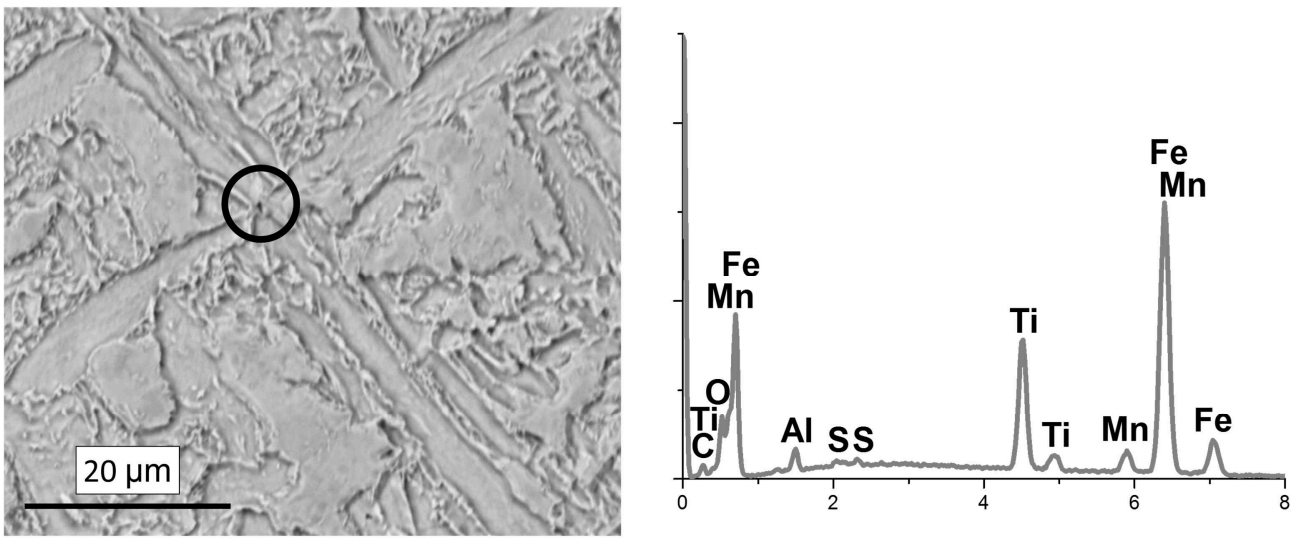

Fig.6. SEM/EDS-analysis of an active inclusion for the nucleation of acicular ferrite.

\section{Summary and Conclusion}

The formation of acicular ferrite is mainly influenced by cooling rate as well as steel composition and non-metallic inclusions - the latter strongly affected by deoxidation practice. These parameters interact significantly. Thus, for the determination of the most decisive influencing factors regarding the formation of acicular ferrite, a systematic study concerning the different influencing parameters and their interactions is indispensable. Within the present work, the influence of Ti-content and different cooling conditions on the microstructure of HSLA steels were investigated systematically on laboratory scale using a so-called dipping test simulator.

The results of these experiments are summarized in Fig.7. The maximum amount of acicular ferrite was achieved for a titanium content of $0.05 \%$ and a cooling rate of $7^{\circ} \mathrm{C} / \mathrm{s}$.

\begin{tabular}{|c|c|c|c|c|c|}
\hline & $\mathbf{0 , 0 5 \%} \mathbf{T i}$ & $\mathbf{0 , 1} \% \mathbf{T i}$ & $\mathbf{0 , 2} \% \mathbf{T i}$ & $\mathbf{0 , 3 6 \%} \mathbf{T i}$ & $\mathbf{0 , 4 5 \%} \mathbf{~ T i}$ \\
\hline $\mathbf{V 1}$ & $\mathrm{M}$ & $\mathrm{M}$ & $\mathrm{M}$ & $\mathrm{M}$ & $\mathrm{M}$ \\
\hline $\mathbf{V 2}$ & $\mathrm{B} / \mathrm{M}$ & $\mathrm{B} / \mathrm{M}$ & $\mathrm{B} / \mathrm{M}$ & $\mathrm{B} / \mathrm{M}$ & $\mathrm{B} / \mathrm{M}$ \\
\hline $\mathbf{V 3}$ & $\mathrm{AF}$ & $\mathrm{B} / \mathrm{AF}+\mathrm{B} / \mathrm{M}$ & $\mathrm{B} / \mathrm{M}$ & $\mathrm{B} / \mathrm{M}$ & $\mathrm{B} / \mathrm{M}$ \\
\hline $\mathbf{V 4}$ & $\begin{array}{c}\mathrm{AF}+\mathrm{WF}+ \\
\mathrm{GBF}+\mathrm{B} / \mathrm{M}\end{array}$ & $\begin{array}{c}\mathrm{B} / \mathrm{AF}+ \\
\mathrm{B} / \mathrm{M}\end{array}$ & $\mathrm{B} / \mathrm{M}$ & $\mathrm{B} / \mathrm{M}$ & $\mathrm{B} / \mathrm{M}$ \\
\hline
\end{tabular}

Fig.7. Microstructure in dipping samples dependent of Ti-content and cooling rate.

Using dipping tests for this examination proved that acicular ferrite can not only be produced by heat treatments (thermo-mechanical treatments or welding). Acicular ferrite microstructures also form after solidification and during subsequent cooling due to non-metallic inclusions acting as heterogeneous nuclei. These inclusions mostly show a multiphase structure, which is in good accordance with literature, where also complex inclusions are described as particularly active for acicular ferrite nucleation.

Summing up, using a defined and controlled deoxidation and desulphurization practice active inclusions for the formation of acicular ferrite can be formed. No separate addition of inclusion particles was necessary for heterogeneous nucleation. Thus, the used experimental set-up of dipping tests is seen as an adequate tool for the examination of various influence parameters on the nucleation of acicular ferrite. Combining dipping tests with several analytical methods - e.g. manual and automated SEM/EDS-analyses - enables an intensive study of inclusion landscape. Chemical composition, inclusion size and morphology of active inclusions for the nucleation of acicular ferrite can be determined. Based on this knowledge, this experimental set-up will be used in future for the detailed examination of the effect of different inclusions on acicular ferrite formation. 


\section{Acknowledgements}

The authors are grateful for the financial supports from the Federal Ministry for Transport, Innovation and Technology (bmvit) and the Austrian Science Fund (FWF): [TRP 266-N19].

\section{References}

[1] H. Goto, K.-I. Miyazawa and T. Kadoya, Effect of the Composition of Oxide on the Reaction between Oxide and Sulfur during Soldification of Steels, ISIJ International 35, 12 (1994) 14771482 .

[2] H. Goto, K.-I. Miyazawa, W. Yamada and K. Tanaka, Effect of Cooling Rate on Composition of Oxides Precipitated during Solidification of Steels, ISIJ International 35, 6 (1995) 708-714.

[3] S. Liu and D.L. Olson, The Influence of Inclusion Chemical Composition on Weld Metal Microstructure, Journal Materials Engineering 9 (1987) 237-251.

[4] S.S. Babu, F. Reidenbach, S.A. David, T. Böllinghaus and H. Hoffmeister, Effect of high energy density welding processes on inclusion and microstructure formation in steel welds, Science and Technology of Welding and Joining 4, 2 (1999) 63-73.

[5] S.S. Babu, S.A. David and J.M. Vitek, Effect of oxide inclusions on the solid state transformations in low-alloy fusion welds, 4th International Conference on Trends in Welding Research, Gatlinburg, USA, 1995, 1-7.

[6] S. Ohkita and Y. Horii, Recent Developments in Controlling the Microstructure and Properties of Low Alloy Steel Weld Metals, ISIJ International 35, 10 (1995) 1170-1182.

[7] D.S. Sarma, A.V. Karasev and P.G. Jönsson, On the Role of Non-metallic Inclusions in the Nucleation of Acicular Ferrite in Steels, ISIJ International 49, 7 (2009) 1063-1074.

[8] C. van der Eijk, O. Grong and J. Hjelen, Quantification of Inclusion-Stimulated Ferrite Nucleation in Wrought Steel using the SEM-EBSD Technique, Proceedings of the International Conference on Solid State Phase Transformations, JIM, Sendai, Japan, 1999, 1573-1576.

[9] J.-L. Lee and Y.-T. Pan, The Formation of Intergranular Acicular Ferrite in Simulated Heataffected Zone, ISIJ International 35, 8 (1995) 1027-1033.

[10]Z. Zhang and R.A. Farrar, Role of non-metallic inclusions in formation of acicular ferrite in low alloy weld metals, Materials Science and Technology 12 (1996) 237-260.

[11]J.-H. Shim, Y.-J. Oh, J.-Y. Suh, W. Cho, J.-D. Shim, J.-S. Byun and D.N. Lee, Ferrite Nucleation potency of non-metallic inclusions in medium carbon steels, Acta Materialia 49 (2001) 2115-2122.

[12]J.-S. Byun, J.-H. Shim, Y.W. Cho and D.N. Lee, Non-metallic inclusion and intergranular nucleation of ferrite in Ti-killed C-Mn steel, Acta Materialia 51 (2002) 1593-1606.

[13]H. Mabuchi, R. Uemori and M. Fujioka, The Role of Mn Depletion in Intra-Granular Ferrite Transformation in the Heat Affected Zone of Welded Joints with Large Heat Input in Structural Steels, ISIJ International 36, 11 (1996) 1406-1412.

[14]B. Linzer, C. Bernhard and G. Hohenbichler, Experimental simulation of strip casting, BHM 149 (2004), 107-111.

[15] B. Linzer, G. Hohenbichler, S. Bragin, G. Arth and C. Bernhard, Experimental Simulation of the Solidification of Steel at Higher Cooling Rates, BHM 154 (2009), 498-503. 